\title{
Correction to: Neighbourhood stories: role of neighbour identity, spatial location and order of arrival in legume and non-legume initial interactions
}

\author{
Emanuela W. A. Weidlich • Vicky M. Temperton • \\ Marc Faget
}

Published online: 6 January 2018

(C) Springer International Publishing AG, part of Springer Nature 2017

\section{Correction to: Plant Soil}

https://doi.org/10.1007/s11104-017-3398-3

The original version of this article unfortunately contained a mistake. Figures 2 and 3 were published erroneously.

Figures have now been corrected.

The online version of the original article can be found at https://doi. org/10.1007/s11104-0173398-3

E. W. A. Weidlich • V. M. Temperton · M. Faget Institute for Bio \& Geosciences (IBG-2), Plant Sciences, Forschungszentrum Jülich GmbH, Wilhelm-Johnen-Straße, 52428 Jülich, Germany

V. M. Temperton

e-mail: vicky.temperton@leuphana.de

M. Faget

e-mail: marc.faget@gmail.com

E. W. A. Weidlich $(\bowtie) \cdot$ V. M. Temperton Institute of Ecology, Leuphana University Lüneburg, Scharnhorststraße 1, 21335 Lüneburg, Germany e-mail: emanuela.weidlich@leuphana.de 
Fig. 2 Effects of the treatments on maize aboveground biomass, leaf $\% \mathrm{~N}$ and $\mathrm{C} / \mathrm{N}$. Treatments names are explained in Fig. 1a. The values are means plus/minus one standard error of the mean. Different letters show significant differences between treatments (ANOVA followed by a Newman and Keuls test, $P<0.05$ )
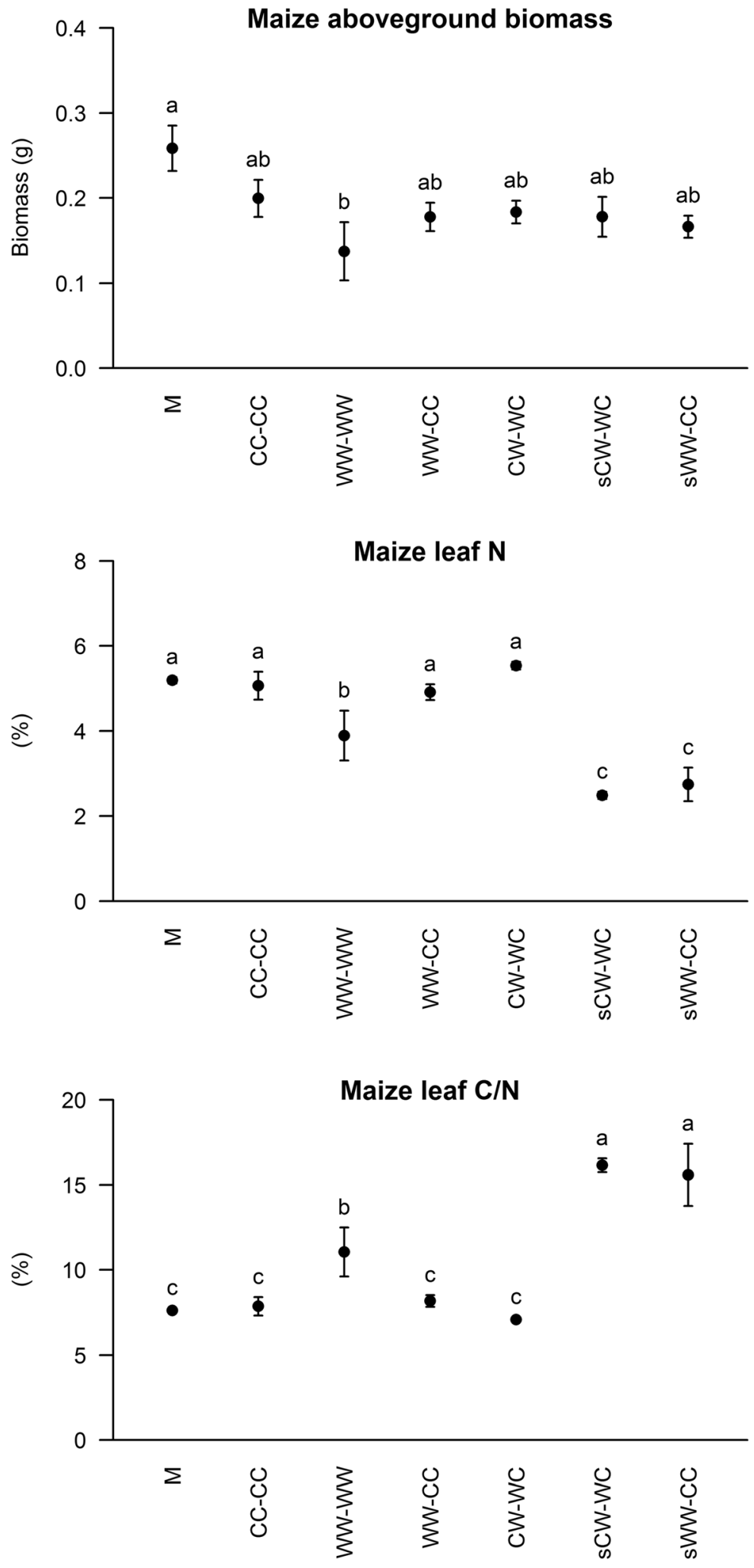
Fig. 3 Effects of the treatments on maize total, lateral and first order root length density.

Treatments names are explained in Fig. 1a. The values are means plus/minus one standard error of the mean. Different letters show significant differences between treatments (ANOVA followed by a Newman and Keuls test, $\mathrm{P}<$ 0.05 )
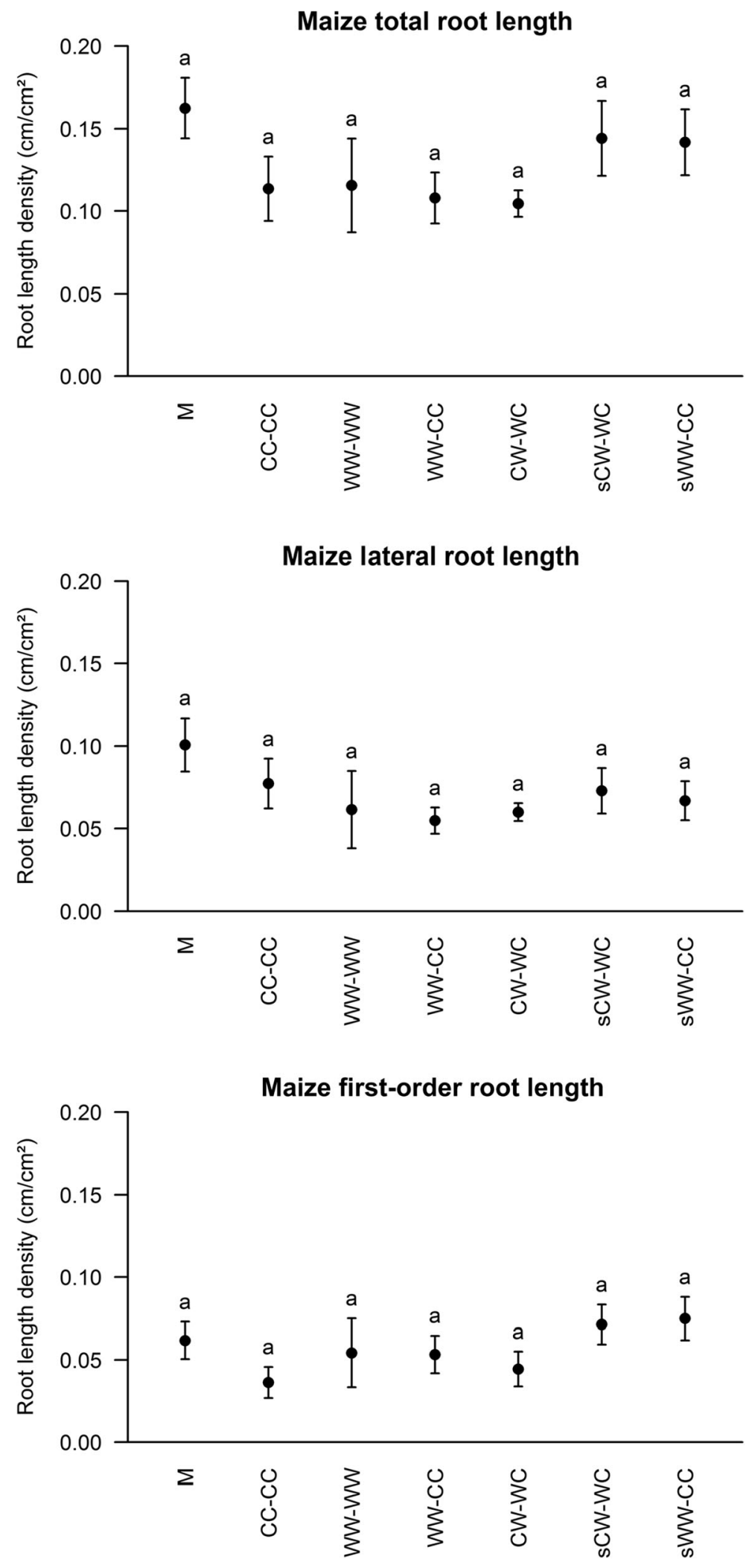